\title{
Comparison of image quality using a X-ray stereotactical whole-body system and a direct flat-panel X-ray device in examinations of the pelvis and knee
}

\section{Bildqualitativer Vergleich eines röntgenstereotaktischen Ganzkörper- aufnahmesystems mit der direkten Flachdetektor-Radiografie anhand von Untersuchungen des Beckens und des Knies}

Authors

Affiliations
K. B. Krug ${ }^{1}$, C. Weber ${ }^{1}$, H. Schwabe', N.-M. Sinzig' ${ }^{1}$, B. Wein ${ }^{2}$, D. Müller ${ }^{1}$, K. Wegmann ${ }^{3}$, S. Peters ${ }^{4}$, V. Sendler ${ }^{4}$, K. Ewen ${ }^{4}$, M. Hellmich ${ }^{5}$, D. Maintz ${ }^{1}$

Affiliation addresses are listed at the end of the article.
Key words

- skeletal-axial

- extremities

- digital radiography

- technology assessment

received 12.6.2013 accepted $\quad 12.7 .2013$

Bibliography DOI http://dx.doi.org/ 10.1055/s-0033-1350441 Published online: 2.9.2013 Fortschr Röntgenstr 2014; 186: 67-76 @ Georg Thieme Verlag KG Stuttgart · New York · ISSN 1438-9029

\section{Correspondence}

Prof. Dr. Kathrin Barbara Krug

Institut für Radiologische Diagnostik, Klinikum der Universität zu Köln Joseph-Stelzmann-Str. 9 50931 Köln

Tel.: ++49/2 21/4785661 Fax: ++49/221/4786787 barbara.krug@uk-koeln.de

\section{Abstract}

$\nabla$

Purpose: The novel biplanar X-ray unit "EOS", EOS Imaging, allows to acquire simultaneously 2 perpendicular planes of full-length spine and limbs and to measure spatially correct angles based on the acquired image data sets. This is to be seen alongside with a low spatial resolution, high investment costs and high operating expenses. The use of the biplanar X-ray unit in morphology based scelettal radiography might improve the cost-benefitrelation. Thus, the purpose of this study was to compare image quality of the EOS-unit and the flat panel (FP)-technology as reference in a clinical setting.

Materials and Methods: All 114 patients of the Orthopedic Hospital Dept., who had a biplanar full-length lower limb radiograph and a FP-examination of the pelvis and/or the knee with maximum time interval of 3 months without changes in the clinical and radiological findings were included in the study. All X-ray examinations had been carried out due to clinical indications. Secondary captures comparable to the FP-images were extracted from the electronic EOS-image data sets. 4 radiologists independently from each other compared the visualization of normal anatomical structures of the pseudonymous EOS- and FP-images in a randomized order.

Results: In the overwiew of all readers and all sceletal regions image quality of the FP-images was considered being superior in a mean of $83 \pm 13 \%$ standard deviation of the pair comparisons (minimum 48\%, maximum $100 \%)$. Image quality of the EOS-images was assessed as being superior in $2 \pm 3 \%$ of the cases $(0 \%, 10 \%)$. Image quality of $0.8 \pm 3 \%$ of the FP-images $(0 \%, 17 \%)$ and $30 \pm 34 \%(0 \%$, $100 \%)$ of the EOS-images was estimated as di- agnostically inadequate. $30 \pm 33 \%$ of the pair comparisons $(0 \%, 100 \%)$ showed a diagnostically inadequate image quality of the EOSimages and a diagnostically good image quality of the FP-images.

Conclusion: Image quality of biplanar fulllength lower limb X-ray examinations is not suitable to be used for the diagnostic assessment of the morphological bone structure using the currently available technological setting.

Key points:

- biplanar full-length lower limb X-ray examinations

- plat-panel radiography

- image quality

Citation Format:

- Krug KB, Weber C, Schwabe H etal. Comparison of image quality using a X-ray stereotactical whole-body system and a direct flat-panel X-ray device in examinations of the pelvis and knee. Fortschr Röntgenstr 2014; 186: 67-76

\section{Zusammenfassung \\ $\nabla$}

Ziel: Das System „EOS“, EOS Imaging, ermöglicht erstmals die simultane Röntgenuntersuchung größerer Skelettabschnitte in 2 Ebenen und die Messung räumlich exakter Winkel anhand der beiden simultan erhobenen Bilddatensätze. Dem stehen eine niedrige Ortsauflösung und hohe Investitions- und Betriebskosten gegenüber. Eine Verbesserung der Kosten-Nutzen-Relation ist durch den zusätzlichen Einsatz des Verfahrens in der morphologischen Skelettdiagnostik denkbar. Daher sollte beantwortet werden, ob die Bildqualität der EOS-Technologie der der Flachdetektor (FD)-Technik als dem Referenzstandard in der klinischen Routinediagnostik vergleichbar ist. 
Material und Methoden: In die Auswertung wurden alle $114 \mathrm{~Pa}-$ tienten der Orthopädischen Klinik eingeschlossen, bei denen in einem maximalen Zeitabstand von 3 Monaten ohne klinischradiologische Befundänderung eine EOS-Ganzbeinuntersuchung und eine FD-Untersuchung des Beckens und/oder des Knies vorlagen. Aus den elektronischen Bilddatensätzen der sagittalen Ganzbeinaufnahmen wurden den FD-Aufnahmen entsprechende Bildausschnitte angefertigt. Die pseudonymisierten EOS- und FDBilder wurden bezüglich der Abbildungsgüte anatomischer Strukturen in randomisierter Reihenfolge durch 4 Radiologen unabhängig voneinander ausgewertet.

Ergebnisse: In der Zusammensicht aller Auswerter und Skelettregionen wurde die FD-Technologie im Mittel bei $83 \pm 13 \%$ Standardabweichung der Paarvergleiche (Minimum $48 \%$, Maximum $100 \%$ ) und die EOS-Bilder bei $2 \pm 3 \%$ Standardabweichung der Paarvergleiche $(0 \%, 10 \%)$ als bildqualitativ überlegen eingestuft. $0,8 \pm 3 \%$ der FD-Bilder $(0 \%, 17 \%)$ und $30 \pm 34 \%$ der EOS-Bilder $(0 \%, 100 \%)$ wurden als diagnostisch ungenügend bewertet. $30 \pm$ $33 \%(0 \%, 100 \%)$ der Paarvergleiche ergaben eine diagnostisch unzureichende Einstufung der EOS-Bilder und eine diagnostisch adäquate Bewertung der FD-Aufnahmen.

Schlussfolgerung: Die Bildqualität der EOS-Ganzbeinaufnahmen ist mit der derzeit verfügbaren Detektortechnologie in Bezug auf die morphologische Diagnostik der Knochenstruktur im Vergleich zur FD-Technik unterlegen.

\section{Introduction}

For the first time worldwide, the multidimensional X-ray whole body imaging system EOS (EOS Imaging, Paris, France) allows simultaneous acquisition of overview images of several related body regions in 2 perpendicular planes [1-3]. The system consists of a 2.7 meter tall housing in which 2 CT X-ray tubes are arranged perpendicular to one another. The height, speed and collimation are coordinated between the two sources and move across the body region to be imaged while continuously releasing $\mathrm{X}$-radiation. The $X$-rays emitted by the patient are registered by 2 perpendicularly arranged xenon gas detectors synchronized with both CT X-ray tubes. The particle detector system is based on the principle of charge multiplication in gas under high pressure; the result is electronic multiplication of the signals emitted by the examination volumes [ $1-3]$. The intensity of the scattered radiation sensed by this linear detector is reduced by a slot diaphragm in order to improve the signal-to-noise ratio at the detector input. According to the literature, increasing the amplitude of the measured signal permits a reduction of the exposure dose compared to digital flat panel detector and storage phosphor systems [1 - 3]. This instrument technology does not meet all the technical requirements listed in the Expert and Examination Guidelines (SV-RL) for operating medical X-ray devices [4]. This essentially refers to the requirements for a spatial high contrast resolution capacity of at least $2.4 \mathrm{lp} / \mathrm{mm}$, automatic exposure control and use of a special filter for images of the trunk of children 12 years of age and under. Due to the specified detector element pixel size of $250 \mu \mathrm{m}$, the high-contrast resolution of the EOS system, when a system dosage is set corresponding to $400 \mathrm{FFS}$, is $2.0 \mathrm{lp} / \mathrm{mm}$ instead of the required $2.4 \mathrm{lp} / \mathrm{mm}$. Automatic exposure controls used for flat-configured radiography systems (flat panel detectors, storage phosphors) using the principle of dosing via a measuring chamber attached to the image receptor cannot be implemented when line scanners such as the EOS system are used [5]. It is generally accepted that such X-ray equipment can be operated using preprogrammed settings.

Although the EOS technology offers intrinsic advantages of exact 3-dimensional measurement of joint angles and relatively low exposure dose, there are disadvantages including the relatively low spatial resolution of the detector, lack of automatic exposure control, the inability to acquire images of entire spinal columns occasionally required in specialty clinics. In addition, high investment and operating costs also pose a disadvantage $[2,6]$. In order to increase the cost-benefit ratio, utilization of EOS technology in morphological skeletal and joint diagnosis has been discussed. For this reason, the Cologne district government, as the competent nuclear supervisory authority, at the request of the Ministry of Labor, Integration and Social Affairs of North Rhine Westphalia issued an opinion to clarify whether the requirements of SV-RL regarding image quality and general equipment of the EOS system would be equivalently fulfilled so that the prerequisites under Paragraph 3, Sentence 2, no. 5 and Sentence 3 no. $2 \mathrm{a}$ and b of the X-ray Ordinance would be met [5]. Within the scope of the evaluation, the imaging precision of the EOS system was compared to a flat panel detector system (Digital Diagnost, Philips Healthcare) using measurements with the contrast-detail phantom (CDRAD type 2.0, Artinis). The results of in vitro measurements indicated similar imaging quality of both examination methods. An evaluation of the diagnostic image quality was not the subject matter of the assessment. Based on this study, at the request of the state and district government, the diagnostic image quality of the EOS technology should be compared with that of digital flat technology as the reference standard. The project sought to concretely answer whether in retrospect a sagittal flat panel detector image might be dispensed in favor of an EOS image in the case of patients, in whom a full-leg examination was performed to diagnose synchronous or metachronous position relationships, a pelvic image or X-ray examination had been performed without any intervening change in findings.

\section{Materials and Methods \\ $\nabla$}

\section{Examination Technologies}

The EOS X-ray stereotactic whole body imaging system produced by EOS Imaging, Paris, France, had been on loan in the Orthopedic Radiology department of the Radiological Institute since 09/2010. From 09/2010 to 02/2011 the data acquisition and image reconstruction algorithm implemented in the system was optimized with the support of the manufacturer. Since the signal-to-noise ratio of $2 \mathrm{D}$ documentation in the area of the trunk when the exposure parameters implemented by the vendor did not provide sufficiently reliable detection of anatomical landmarks during automatic angle determination, the specified exposure parameters were raised with the help of the manufacturer. By mutual agreement, the originally specified values were individually adapted from $80 \mathrm{kV}$ up to $95 \mathrm{kV}$ and $200 \mathrm{mAs}$ up to $320 \mathrm{mAs}$ for normal weight and obese patients in order achieve opti- 
mum image quality in relation to radiation exposure. Likewise, supported by the manufacturer, the image calculation algorithms of the EOS system were optimized and adapted to the image characteristics of the flat panel detector systems. Since 04/2011, a special imaging calculation algorithm was available for previously acquired image data sets. This product of EOS Imaging was designed to minimize elimination artifacts at the borders of endoprotheses.

Creation of the overview images used the following equipment: 2 digital flat panel detector work stations (Digital Diagnost, Philips Healthcare) with a scintillator layer of cesium iodide, a usable detector surface of $43 \times 43 \mathrm{~cm}$, a $3000 \times 3000$ pixel matrix, pixel size with a $0.143 \mathrm{~mm}$ edge length, 14-bit gray value depth and a nominal DQE (Detective Quantum Efficiency) of $65 \%$.

\section{Patients}

During the period 03/01/2011 to 10/31/2011, all 214 patients of the Orthopedic University Clinic were prospectively identified; these patients had undergone a whole leg examination in the course of their medical care. In the related evaluation of image quality, those whole leg examinations were included in which X-ray examinations of the pelvis or knee were performed in the course of medical care within a maximum interval of 3 months without changes of the clinical-radiological findings in the meantime. In the case of patients with whole leg examinations and/or flat panel detector images meeting inclusion criteria, the chronologically initial examination was selected for assessment. If radiographic images of both knee joints taken at the same time were available, then alternately the right and left side from patient to patient were included in the evaluation in order to avoid giving excess weighting to the aspect ratios of an individual patient, and thereby influencing the results.

Between 09/2011 and 11/2011, two members of the working group (B. K., C.W.), using the SterEOS ${ }^{\circledast}$ console prepared comparison image sections of the pelvis or knee relative to the framing of the flat panel detector. These images were based on the electronic records of sagittal full leg images of each patient. Oblique or lateral images were rejected in both of the two technologies, since in the pelvis and hip joint region there were no lateral flat panel detector images, and since lateral EOS images of the knee joint were generally negatively affected by overlapping of the contralateral knee. In addition, the EOS and flat panel detector images were pseudonymized and assigned random numbers when stored in the SterEOS ${ }^{\circledR}$ image processing console.

\section{Image Evaluation Process}

Starting in 04/2012 the EOS and flat panel detector images were evaluated in random order by 4 radiologists (B.K., N.-M.S., H.S., B.W.) using an electronic data collection form while working independently using the SterEOS ${ }^{\circledR}$ work station. The form was employed to sample the image quality of normal anatomical structures and neocorticals along the metal implants using a 6-stage assessment scale from 1: "anatomical structure well-delineated in all sections" to 6: "anatomical structure not delineated". During the assessment it was not revealed whether the image sources were from were EOS or flat panel detectors. A time interval of at least 4 months was established between the preparation of the images and the start of the evaluation in order to prevent the assessors from remembering the image pair correlations. Three assessors were specialist physicians in radiology (B.K., H.S., B.W.); one assessor was in third year medical residency as a radiologist (N.-M.S.). Two assessors (B. K., B. W.) possessed long years of experience in evaluating digital projection radiography.

\section{Statistical Evaluation}

The assessors' notations were recorded in an IT-supported dialog using Excel (Microsoft Corp., Redmond, WA, USA). Statistical analysis were performed using SPSS Statistics (IBM Corp., Armonk, NY, USA).

The patient-related pairings of EOS and flat panel detector images formed the basis for the statistical evaluation. Following this were the paired comparisons of various related anatomical regions: right/left os ileum and upper os sacrum, relating to the large pelvis region; likewise compared were right/left acetabulum, right/left os pubis, right femoral head, right femoral neck, right greater trochanter, right proximal femoral diaphysis; left femoral head, left femoral neck, left greater trochanter and left proximal femoral diaphysis relating to the small pelvis/hip. Likewise considered were the paired comparisons of the anatomical regions distal femoral diaphysis, condylus medialis, basis patellae, intercondylar eminence, tibial metaphysis, and proximal fibula relating to the general knee region. The notations of every assessor for each collective region were collected and presented as indications of mean values, standard deviations, minimum and maximum as well as box and whiskers plots in the general overview and for secondary issues.

\section{Results \\ $\nabla$}

Key Patient and Examination Data

Between 03/01/2011 and 10/31/2011, the EOS system was initially used for whole-leg examinations of 114 patients for whom there were no clinical-radiological changes over a maximum of 3 months determined by findings based on overview images using a flat panel detector system. Of these, 62 patients underwent pelvic imaging $(54.4 \%)$ and 55 patients $(48.2 \%$ ) had knee joint imaging. Three patients (2.6\%) fulfilled the inclusion criteria for pelvic overview imaging as well as X-ray imaging of the knee joint. The time interval between both examinations was on average 6.7 days \pm 14.4 days standard deviation (minimum 0 days, maximum 73 days). Of the 114 patients, 64 were female $(56.1 \%)$ and 50 were male (43.9\%). The mean age was 63.7 years \pm 15.0 years standard deviation; the minimum was 20 years, maximum 93 years of age. The cohort included exclusively patients of the Orthopedic University Clinic who had been referred to the radiologist due to clinical complaints, for planning replacement of hip or knee joints, as well as patients referred for postoperative checkups ( $\bullet$ Table 1 ).

The sagittal whole leg images were ranked by body weight produced using the following preset values: one patient with presets of $80 \mathrm{kV}$ and $200 \mathrm{mAs} ; 15$ patients with $85 \mathrm{kV}$ and $200 \mathrm{mAs} ; 2$ patients with $85 \mathrm{kV}$ and $250 \mathrm{mAs} ; 5$ patients with $95 \mathrm{kV}$ and $250 \mathrm{mAS}$; 54 patients with $95 \mathrm{kV}$ and $320 \mathrm{mAs}$; one patient with $100 \mathrm{kV}$ and $400 \mathrm{mAs} ; 5$ patients with $104 \mathrm{kV}$ and $320 \mathrm{mAs}$; 30 patients with $104 \mathrm{kV}$ and $400 \mathrm{mAs}$, as well as one patient with $125 \mathrm{kV}$ and $320 \mathrm{mAs}$. 
Tab. 1 Clinical data.

\begin{tabular}{|lll|}
\hline Characteristic & $\begin{array}{l}\text { Number of } \\
\text { patients } \\
\text { (n) }\end{array}$ & $\begin{array}{l}\text { Number of } \\
\text { patients } \\
\text { (\%) }\end{array}$ \\
\hline patients & 114 & 100 \\
\hline female patients & 64 of 114 & 56.1 \\
\hline male patients & 50 of 114 & 43.9 \\
\hline indications & \multicolumn{2}{|c|}{} \\
\hline pelvis overview images & 62 & 100 \\
\hline clinical symptoms & 17 of 62 & 27.4 \\
\hline planning a hip TEP & 22 of 62 & 35.4 \\
\hline control after a current implantation of a hip TEP & 12 of 62 & 19.4 \\
\hline symptoms after an old implantation of a hip TEP & 11 of 62 & 17.8 \\
\hline knee overview images & 55 & 100 \\
\hline clinical symptoms & 16 of 55 & $29, .1$ \\
\hline planning a knee TEP & 17 of 55 & 30.9 \\
\hline control after a current implantation of a hip TEP & 17 of 55 & 30.9 \\
\hline symptoms after an old implantation of a hip TEP & 5 of 55 & 9.1 \\
\hline & & \\
\hline
\end{tabular}

TEP = Total prosthetic replacement

The mean dose area product for all sagittal whole leg images was $12.5 \mathrm{cGyc} \times \mathrm{cm}^{2} \pm 4.1 \mathrm{cGyc} \times \mathrm{cm}^{2}$ (minimum 4.5 $\mathrm{cGyc} \times \mathrm{cm}^{2}$, maximum $\left.19.6 \mathrm{cGyc} \times \mathrm{cm}^{2}\right)(\diamond$ Table 2$)$.

62 sagittal examinations were prepared with $77 \mathrm{kV}$ (59 examinations) or $81 \mathrm{kV}$ (3 examinations). On average the charge was $19.01 \mathrm{mAs} \pm 11.34 \mathrm{mAs}$ (4.00 mAs, maximum $67.00 \mathrm{mAs}$ ) and the dose area product was $17.6 \mathrm{cGyc} \times \mathrm{cm}^{2}$ $\pm 11.0 \mathrm{cGyc} \times \mathrm{cm}^{2}$ (minimum $3.8 \mathrm{cGyc} \times \mathrm{cm}^{2}$, maximum 56.6 cGyc $\times \mathrm{cm}^{2}$ ) ( Table 2). The same values applied to the 55 sagittal examination of the knee: $66 \mathrm{kV}$ (54 examinations) and $70 \mathrm{kV}$ ( 1 examination) as well as $7.62 \mathrm{mAs}$ $\pm 3.89 \mathrm{mAs}$ (24.30 mAs, maximum $2.30 \mathrm{mAs}$ ), corresponding to a dose area product of $2.2 \mathrm{cGyc} \times \mathrm{cm}^{2} \pm 1.2 \mathrm{cGyc} \times \mathrm{cm}^{2}$ (minimum $0.3 \mathrm{cGyc} \times \mathrm{cm}^{2}$, maximum $6.8 \mathrm{cGyc} \times \mathrm{cm}^{2}$ ).

\section{Image Evaluations}

- Fig. 1 illustrates the ranking for each assessor according to the anatomical regions "large pelvis", "small pelvis/hip" and "knee". Assessment used a direct "flat panel detector image" vs. "EOS image" comparison in the form of a box and whispers plot. The image quality of the EOS images was graded inferior to that produced by flat panel detectors; this assessment was unrelated to the assessors' level of training or familiarity with EOS technology (๑ Fig. 2, 3). This applies both to the delineation of corticals and spongiosa structure as well as the neocortical boundary lamella in the case of osteosynthetic implants. The results were not dependent on the thickness of the X-rayed body region.

In the general view of all assessors with respect to all examined skeletal regions, flat panel detector technology produced $82.6 \% \pm 13.2 \%$ qualitatively superior image pairs, whereas $2.0 \% \pm 2.6 \%$ of EOS images were ranked as superior ( $\triangle$ Table 3 ). Where $0.8 \% \pm 3.2 \%$ of the flat panel detector images were graded " 5 " or " 6 ", i. e. diagnostically insufficient, $29.9 \% \pm 33.9 \%$ of the EOS images were considered insufficient. In the overview of all assessors and of all skeletal regions a constellation of the evaluation of flat panel detector images were considered diagnostically insufficient (rated "5" or "6"), compared to a diagnostically good rating of corresponding EOS images (rating "1" or " 2 ") was 0.1 $\pm 0.4 \%$. Conversely, $29.9 \pm 32.9 \%$ of the EOS image pairs were rated diagnostically insufficient (rated " 5 " and "6") compared to a flat panel detector images rated as diagnostically good (rated "1" or "2"). The extent of the results was continually confirmed by the individual assessors with respect to examined regions ( $\bullet$ Table 3 ).

\section{Discussion \\ $\nabla$}

Compared to similar technologies on the market, the EOS $\mathrm{X}$-ray stereotactic whole body imaging system (EIS Imaging, Paris, France) offers the unique selling proposition of providing simultaneous radiographical projections of the entire body or larger body sections in 2 perpendicularly arranged planes. The two image data sets enable the generation of 2-dimensional representations of the examined body region; based on this, the precise angle of complex skeletal structures can be determined in all three planes of the patient's upright position [7-12]. An electronic image fusion of several individual exposures for the generation of full spine and full leg images as in conventional digital imaging systems is eliminated. Special processing algorithms allow semi-automatic generation of a pseudo-3 $\mathrm{D}$ representation of the examined body regions from the biplanar electronic image data sets [ $1-3]$. Here image reconstruction is based on standard data sets of skeletal structures obtained from larger patient cohorts. In the pseudo-3 D images, the lengths and angles of the skeletal section are properly reproduced. However, due to the projected nature of both overview images supporting $3 \mathrm{D}$ imaging, the three-dimensional representation of the skeleton is only virtual. Numerous in vivo and in vitro studies have discussed the accuracy of such angle determinations and their medical utility $[7,8$, $10-14]$.

Since the indications justifying exact three-dimensional radiological determination of skeletal angle in the patient population of an orthopedic specialty clinic compared to conventional skeletal diagnostics are likely to be relatively rare, an X-ray stereotactic system used only for angle and position determination will generally not be fully utilized in the course of daily activities [2,15]. Dietrich et al. compared the processes of EOS technology with the characteristics of standard digital technology (Ysio, Siemens Healthcare) for the generation of 133 whole spine images and 185 whole leg images [15]. According to Dietrich et al. the financial break-even point for Swiss economic circumstances was 4 X-ray stereotactic examinations per work day instead of 3 whole spine examinations performed per work day using the standard system [15]. An increase in utilization frequency and improvement of the operating costs of EOS technology could be achieved if the system could also be used for position verification in morphological skeletal diagnostics.

On the other hand, detector technology with a nominal spatial resolution of $2.0 \mathrm{lp} / \mathrm{mm}$ in the high-contrast range does not meet the requirements of the Expert and Examination Guidelines (SV-RL) [4]. The hypothesis, that high contrast dynamics offset the low spatial resolution, was reviewed analogously to the procedure in digital mammography using in vitro measurements with the contrast detail phantom CDRAD type 2.0 made by Artinis [5]. Similar to the 


\begin{tabular}{|llcccc}
\hline \multicolumn{7}{l}{$\begin{array}{l}\text { dose area product }\left(\mathrm{cGy}^{*} \mathbf{c m}^{2}\right) \\
\text { type of image }\end{array}$} & $\begin{array}{l}\text { number of patients } \\
\text { (N) }\end{array}$ & mean & standard deviation & minimum & maximum \\
\hline whole leg images & 114 & 12.5 & 4.1 & 4.5 & 19.6 \\
\hline pelvis overview images & 62 & 17.6 & 11 & 3.8 & 56.6 \\
\hline knee overview images & 55 & 2.2 & 1.2 & 0.3 & 6.8 \\
\hline
\end{tabular}

Tab. 2 Dose area product

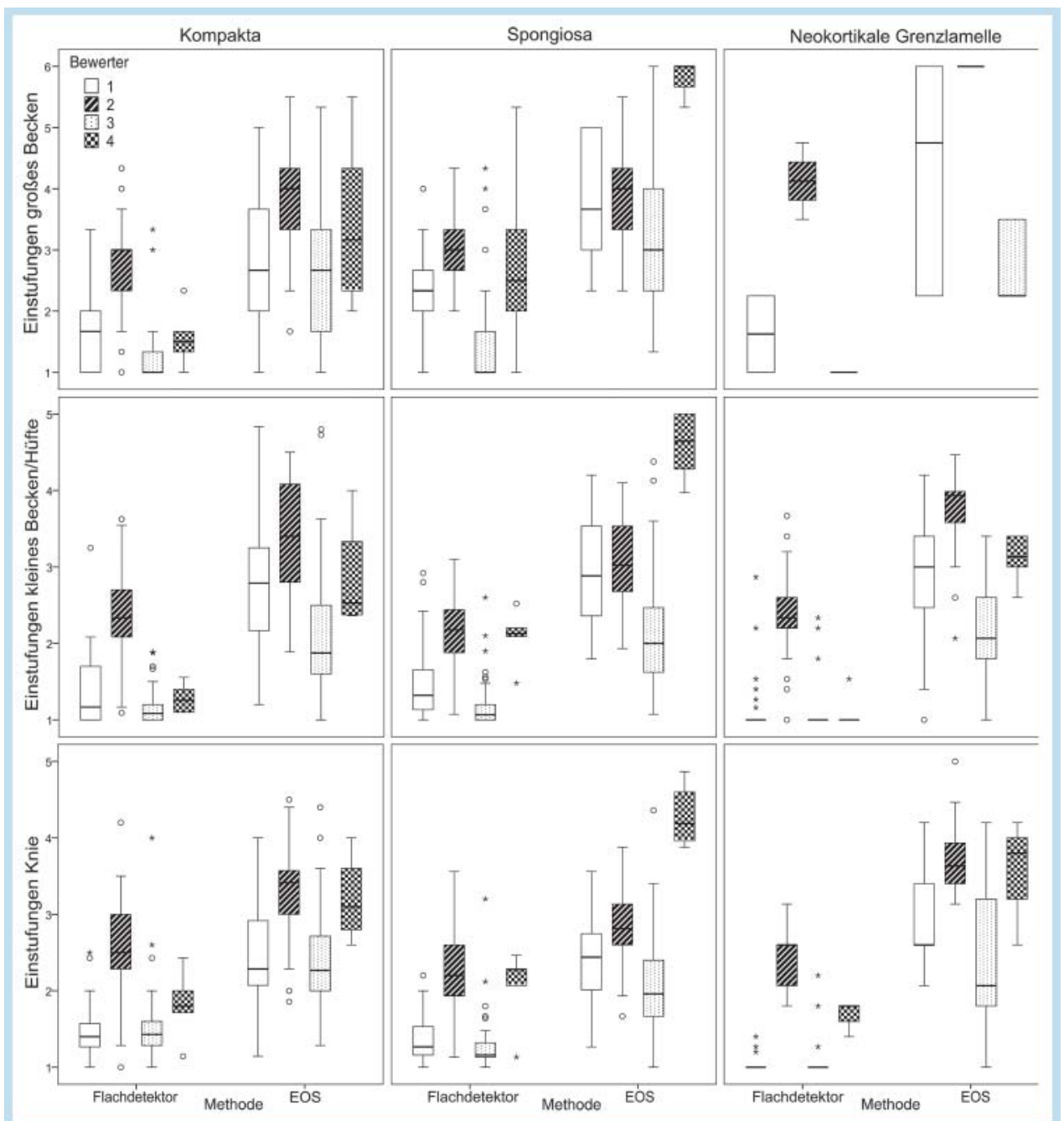

Fig. 1 Box-whiskers plots of the four readers' assessments based on matched pair comparisons. The upper and lower borders of the squares indicate the upper and lower simple standard deviation; the horizontal lines within the squares show the mean values; the broken lines represent the upper and lower double standard deviation; and the circle and star symbols indicate the statistical outliers. The assessments relating to the numbers on the left were: " 1 = Criterion in all sections well-delineated"; " 2 = Majority of sections well-delineated"; "3 Majority of sections satisfactorily delineated"; "4 = Majority sufficiently delineated"; " 5 = Insufficiently delineated”; and " 6 = Not delineated". The differing numbers of matched image comparisons per assessor is because in individual cases, the anatomical region was classified by the assessor as not shown, so a paired comparison was not possible. Upper row: superior region "large pelvis" including the individual regions right os leum, left os ileum, upper os sacrum. For assessors 1 to 3 there were 61,62 and 60 pairs respectively for the criteria "delineation of cortical bone" and "delineation of spongiosa". For the criterion "delineation of neocortical boundary lamella for osteosynthesis material" there were, respectively, 4, 1 and 3 matched images. Assessor 4 evaluated 6 image pairs for the first two criteria and none for the third. Center row: superior region "small pelvis/hip" includes evaluation of the following individual regions: right/left acetabulum, right/left os pubis, right femoral head, right femoral neck, right greater trochanter, right proximal femoral diaphysis; left femoral head, left femoral neck, left greater trochanter and left proximal femoral diaphysis. For assessors 1 to 3 there were 62, 62 and 61 pairs respectively for the criteria "delineation of cortical bone and spongiosa" and "delineation of neocortical boundary lamella" there were, respectively, 44, 43 and 41 matched images. Assessor 4 evaluated 6 image pairs with respect to the first two criteria and 5 with respect to the third. Lower row: superior region "knee" includes evaluation of the following individual regions: distal femoral diaphysis, condylus medialis, basis patellae, eminentia intercondylaris, proximal tibial metaphysis and proximal fibula. For the first two criteria, assessors 1 to 4 had access to 55, 54, 54 and 4 image pairs respectively; for evaluation of the last criteria they had 35, 35, 37 and 2 image pairs respectively. 

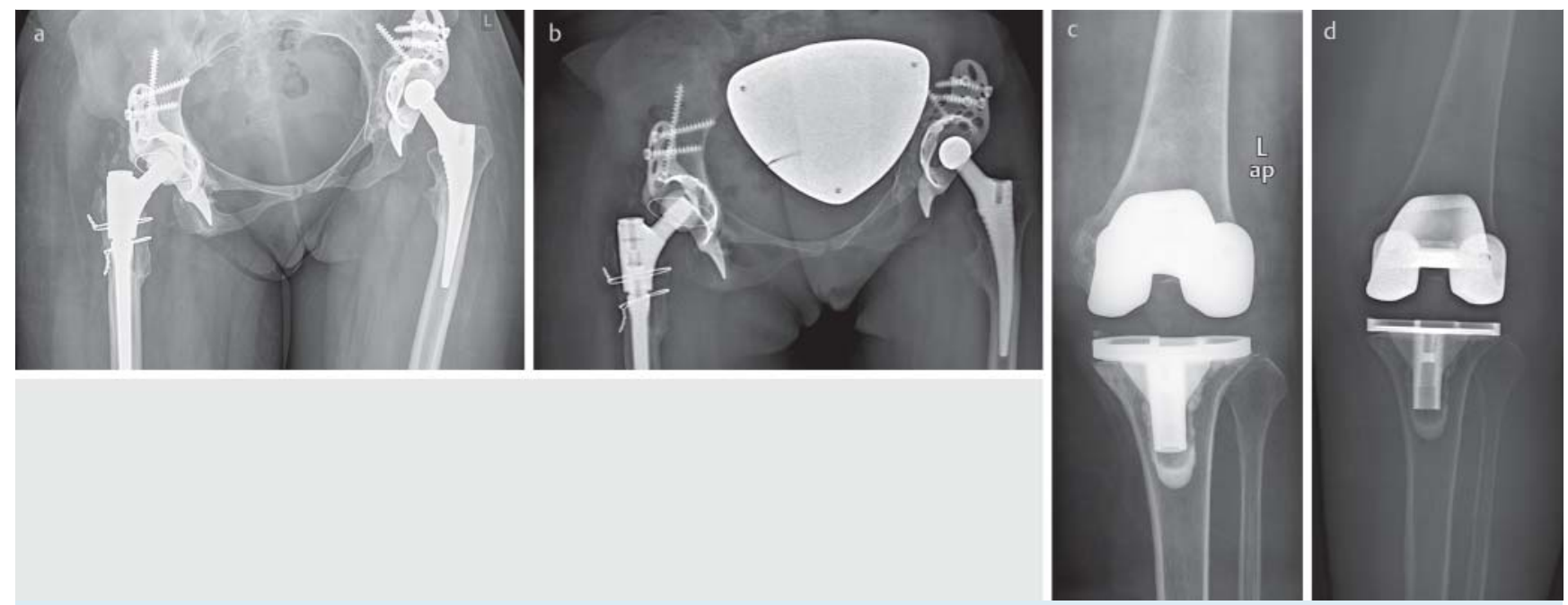

Fig. 2 Matched pair comparisons with the largest differences of the mean assessments of the visualization of the spongiosa of reader 1 in favour of the flat-panel technology. a superior region "pelvis/hip". Flat-panel images. Mean assessments of the region "large pelvis": Reader 1: 1.3, reader 2: 3.3 and reader 3: 1.0 as well as region "small pelvis/hip": Reader 1: 1.1 , reader 2: 2.6 and reader 3: 1.3. b superior region "pelvis/hip". EOS-images. Mean

assessments of the region "large pelvis": Reader 1: 5.0, reader 2: 5.5 and reader $3: 3.7$ as well as superior region "small pelvis/hip": Reader 1: 3.6 , reader 2: 4.5 and reader 3: 2.8 . c superior region "knee". Flat-panel images. Mean assessments of reader $1: 1.2$, of reader $2: 2.0$ and of reader 3: 1.6. d superior region "knee". EOS-images. Mean assessments of reader 1: 4.2, of reader 2: 4.4 and of reader $3: 4.0$.
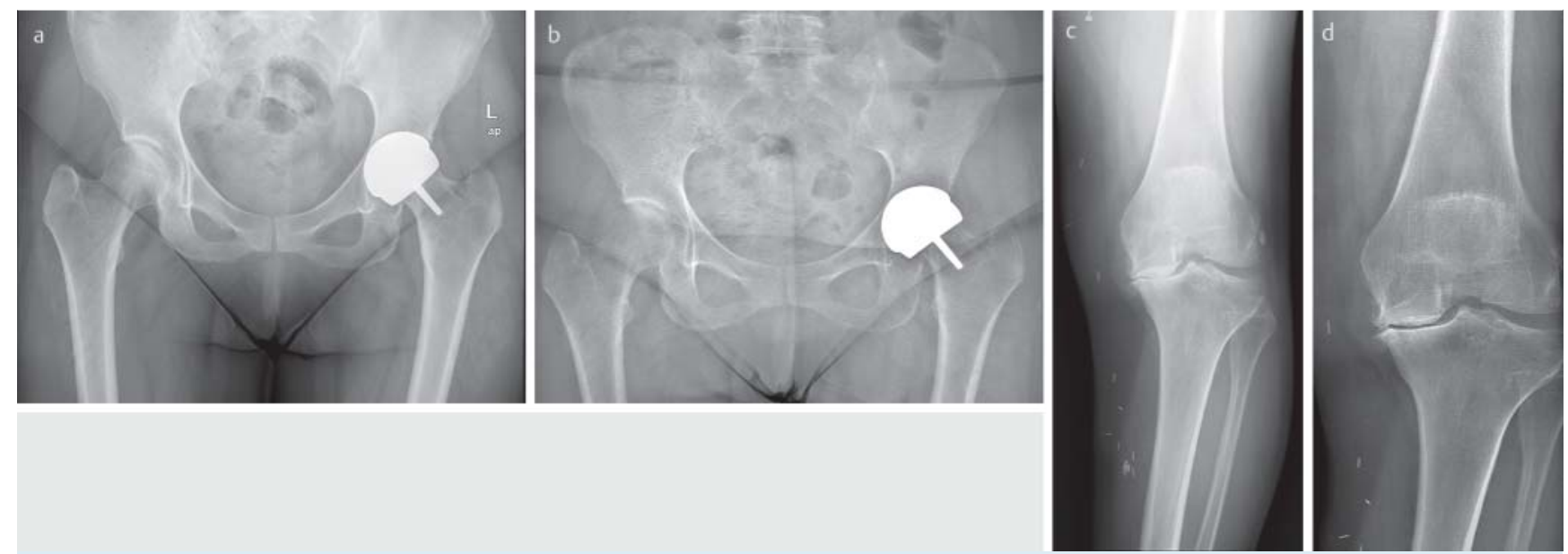

Fig. 3 Matched pair comparisons with the largest differences of the mean assessments of the visualization of the spongiosa of reader 1 in favour of the EOS-technology. a superior region "pelvis/hip". Flat-panel images.

Mean assessments of the region "large pelvis": Reader 1: 3.3, Reader 2: 3.0 and reader 3: 1.0 as well as of the region "small pelvis/hip": Reader 1:1.7, reader $2: 2.4$ and reader $3: 1.1$. b superior region „pelvis/hip“. EOS-images.
Mean assessments of the region "large pelvis": Reader 1: 3.0, reader $2: 4.03$ and reader 3: 2 , as well as of the region "small pelvis/hip": Reader 1: 3.0, reader 2: 3.4 and reader 3: 1.6. c superior region "knee". Flat-panel images. Mean assessments of reader $1: 2.0$, of reader $2: 2.7$ and of reader $3: 1.3$. d superior region "knee”. EOS-images. Mean assessments of reader 1: 1.5, of reader 2: 2.3 and of reader $3: 2.3$.
CDMAM phantom in digital mammography, the CDRAD phantom is used for simultaneous comparison of X-ray systems with respect to their contrast and spatial resolution (contrast resolution capability) [5, 16-20]. The phantom consists of a Plexiglas tablet with 225 squares, arranged in 15 rows and columns with 1 or 2 cylindrical holes. The squares of the first 3 rows each exhibit only one hole. The squares of rows 4 through 15 each have 2 identical holes, whereby one hole lies in the center of the square, and one is located in one of the four corners of the square. Within a row, the depth of the hole increases exponentially while the diameter remains constant (test of contrast resolution). The same applies to diameter within a column while the hole depth remains constant (test of spatial resolution). Using the EOS system, a flat panel detector system (Digital Diagnost, Philips Healthcare), and a digital storage phosphor system (Optimus DR, Philips Healthcare), 9 overview images of the phantom were taken with each system, using comparable imaging parameters $(15 \mathrm{~cm}$ thick PMMA polymethyl methacrylate attenuation element). The flat panel detector and storage phosphor systems used automatic exposure control, focus image receptor distance, $110 \mathrm{~cm}$, focal spot size $1.0 \times 1.0$. The EOS system used focus image receptor distance, $130 \mathrm{~cm}$, focal spot size $0.6 \times 1.3$. The EOS 
Tab.3 Overview of the assessments of the superior anatomical regions "large pelvis", "small pelvis/hip" and "knee" of each assessor for the higher-level anatomical regions as well as the summary of all anatomical regions and all assessors.

\begin{tabular}{|c|c|c|c|c|c|c|c|}
\hline assessor & region & evaluation criterion & $\begin{array}{l}\text { number of asses- } \\
\text { sed individual } \\
\text { regions ( } \mathrm{n} \text { ) }\end{array}$ & mean & $\begin{array}{l}\text { standard } \\
\text { deviation }\end{array}$ & minimum & maximum \\
\hline \multirow[t]{21}{*}{1} & \multirow[t]{7}{*}{ large pelvis } & number of images (n) & 3 & 60 & 1 & 59 & 61 \\
\hline & & superior FD image (\%) & 3 & 85.0 & 5.7 & 78.7 & 89.8 \\
\hline & & insufficient FD image (\%) & 3 & 0.0 & 0.0 & 0.0 & 0.0 \\
\hline & & insufficient FD image, EOS image good (\%) & 3 & 0.0 & 0.0 & 0.0 & 0.0 \\
\hline & & superior EOS image (\%) & 3 & 2.2 & 0.9 & 1.7 & 3.3 \\
\hline & & insufficient EOS image (\%) & 3 & 33.5 & 3.3 & 31.1 & 37.3 \\
\hline & & insufficient EOS image, FD image good (\%) & 3 & 33.5 & 3.3 & 31.1 & 37.3 \\
\hline & \multirow[t]{7}{*}{ small pelvis/hip } & number of images ( $n$ ) & 12 & 51 & 13 & 29 & 62 \\
\hline & & superior FD image (\%) & 12 & 94.1 & 3.0 & 89.8 & 98.3 \\
\hline & & insufficient FD image (\%) & 12 & 0.0 & 0.0 & 0.0 & 0.0 \\
\hline & & insufficient FD image, EOS image good (\%) & 12 & 0.0 & 0.0 & 0.0 & 0.0 \\
\hline & & superior EOS image (\%) & 12 & 0.3 & 0.6 & 0.0 & 1.6 \\
\hline & & insufficient EOS image (\%) & 12 & 22.3 & 9.5 & 8.5 & 37.9 \\
\hline & & insufficient EOS image, FD image good (\%) & 12 & 22.3 & 9.5 & 8.5 & 37.9 \\
\hline & \multirow[t]{7}{*}{ knee } & number of images ( $n$ ) & 6 & 51 & 7 & 37 & 55 \\
\hline & & superior FD image (\%) & 6 & 81.5 & 9.2 & 63.6 & 89.1 \\
\hline & & insufficient EOS image (\%) & 6 & 0.0 & 0.0 & 0.0 & 0.0 \\
\hline & & insufficient FD image, EOS image good (\%) & 6 & 0.0 & 0.0 & 0.0 & 0.0 \\
\hline & & superior EOS image (\%) & 6 & 3.7 & 3.2 & 0.0 & 9.1 \\
\hline & & insufficient EOS image (\%) & 6 & 1.4 & 1.1 & 0.0 & 2.7 \\
\hline & & insufficient EOS image, FD image good (\%) & 6 & 1.4 & 1.1 & 0.0 & 2.7 \\
\hline \multirow[t]{21}{*}{2} & \multirow[t]{7}{*}{ large pelvis/hip } & number of images (n) & 3 & 61 & 2 & 59 & 62 \\
\hline & & superior FD image (\%) & 3 & 70.0 & 2.6 & 67.7 & 72.9 \\
\hline & & insufficient EOS image (\%) & 3 & 2.3 & 3.9 & 0.0 & 6.8 \\
\hline & & insufficient FD image, EOS image good (\%) & 3 & 0.6 & 1.0 & 0.0 & 1.7 \\
\hline & & superior EOS image (\%) & 3 & 8.2 & 1.9 & 6.5 & 10.2 \\
\hline & & insufficient EOS image (\%) & 3 & 23.3 & 16.6 & 12.9 & 42.4 \\
\hline & & insufficient EOS image, FD image good (\%) & 3 & 21.6 & 13.6 & 12.9 & 37.3 \\
\hline & \multirow[t]{7}{*}{ small pelvis/hip } & number of images (n) & 12 & 52 & 13 & 29 & 62 \\
\hline & & superior FD image (\%) & 12 & 74.2 & 4.5 & 68.3 & 83.6 \\
\hline & & insufficient flat detector image (\%) & 12 & 0.0 & 0.0 & 0.0 & 0.0 \\
\hline & & insufficient FD image, EOS image good (\%) & 12 & 0.0 & 0.0 & 0.0 & 0.0 \\
\hline & & superior EOS image (\%) & 12 & 2.9 & 1.6 & 0.0 & 5.7 \\
\hline & & insufficient EOS image (\%) & 12 & 11.3 & 9.1 & 0.0 & 25.7 \\
\hline & & insufficient EOS image, FD image good (\%) & 12 & 11.3 & 9.1 & 0.0 & 25.7 \\
\hline & \multirow[t]{7}{*}{ knee } & number of images (n) & 6 & 51 & 7 & 37 & 54 \\
\hline & & superior FD image (\%) & 6 & 62.4 & 8.1 & 48.1 & 70.4 \\
\hline & & insufficient flat detector image (\%) & 6 & 0.9 & 1.0 & 0.0 & 1.9 \\
\hline & & insufficient FD image, EOS image good (\%) & 6 & 0.3 & 0.8 & 0.0 & 1.9 \\
\hline & & superior EOS image (\%) & 6 & 6.8 & 1.9 & 3.7 & 9.3 \\
\hline & & insufficient EOS image (\%) & 6 & 7.1 & 5.5 & 0.0 & 11.3 \\
\hline & & insufficient EOS image, FD image good (\%) & 6 & 6.5 & 5.2 & 0.0 & 11.1 \\
\hline \multirow[t]{14}{*}{3} & \multirow[t]{7}{*}{ large pelvis } & number of images ( $n$ ) & 3 & 59 & 1 & 58 & 59 \\
\hline & & superior FD image (\%) & 3 & 88.1 & 2.9 & 86.4 & 91.4 \\
\hline & & insufficient flat detector image (\%) & 3 & 1.1 & 1.0 & 0.0 & 1.7 \\
\hline & & insufficient FD image, EOS image good (\%) & 3 & 1.1 & 1.0 & 0.0 & 1.7 \\
\hline & & superior EOS image (\%) & 3 & 3.4 & 0.0 & 3.4 & 3.4 \\
\hline & & insufficient EOS image (\%) & 3 & 17.7 & 5.7 & 13.6 & 24.1 \\
\hline & & insufficient EOS image, FD image good (\%) & 3 & 17.7 & 5.7 & 13.6 & 24.1 \\
\hline & \multirow[t]{7}{*}{ small pelvis/hip } & number of images ( $n$ ) & 12 & 48 & 13 & 26 & 61 \\
\hline & & superior FD image (\%) & 12 & 71.9 & 6.2 & 63.3 & 79.7 \\
\hline & & insufficient flat detector image (\%) & 12 & 0.0 & 0.0 & 0.0 & 0.0 \\
\hline & & insufficient FD image, EOS image good (\%) & 12 & 0.0 & 0.0 & 0.0 & 0.0 \\
\hline & & superior EOS image (\%) & 12 & 1.0 & 1.1 & 0.0 & 3.3 \\
\hline & & insufficient EOS image (\%) & 12 & 6.6 & 3.9 & 0.0 & 11.8 \\
\hline & & insufficient EOS image, FD image good (\%) & 12 & 6.6 & 3.9 & 0.0 & 11.8 \\
\hline
\end{tabular}


Tab. 3 (Continuation)

\begin{tabular}{|c|c|c|c|c|c|c|c|}
\hline assessor & region & evaluation criterion & $\begin{array}{l}\text { number of asses- } \\
\text { sed individual } \\
\text { regions ( } \mathrm{n} \text { ) }\end{array}$ & mean & $\begin{array}{l}\text { standard } \\
\text { deviation }\end{array}$ & minimum & maximum \\
\hline & \multirow[t]{7}{*}{ knee } & number of images ( $n$ ) & 6 & 51 & 7 & 37 & 54 \\
\hline & & superior FD image (\%) & 6 & 73.2 & 8.8 & 63.0 & 87.0 \\
\hline & & insufficient flat detector image (\%) & 6 & 0.6 & 1.0 & 0.0 & 1.9 \\
\hline & & insufficient FD image, EOS image good (\%) & 6 & 0.3 & 0.8 & 0.0 & 1.9 \\
\hline & & superior EOS image (\%) & 6 & 1.9 & 1.7 & 0.0 & 3.7 \\
\hline & & insufficient EOS image (\%) & 6 & 2.1 & 2.1 & 0.0 & 5.4 \\
\hline & & insufficient EOS image, FD image good (\%) & 6 & 1.8 & 2.0 & 0.0 & 5.4 \\
\hline \multirow[t]{21}{*}{4} & \multirow[t]{7}{*}{ large pelvis } & number of images ( $n$ ) & 3 & 6 & 1 & 5 & 6 \\
\hline & & superior FD image (\%) & 3 & 94.4 & 9.6 & 83.3 & 100.0 \\
\hline & & insufficient flat detector image (\%) & 3 & 11.1 & 9.6 & 0.0 & 16.7 \\
\hline & & insufficient FD image, EOS image good (\%) & 3 & 0.0 & 0.0 & 0.0 & 0.0 \\
\hline & & superior EOS image (\%) & 3 & 0.0 & 0.0 & 0.0 & 0.0 \\
\hline & & insufficient EOS image (\%) & 3 & 100.0 & 0.0 & 100.0 & 100.0 \\
\hline & & insufficient EOS image, FD image good (\%) & 3 & 88.9 & 9.6 & 83.3 & 100.0 \\
\hline & \multirow[t]{7}{*}{ small pelvis/hip } & number of images ( $n$ ) & 12 & 5 & 1 & 2 & 6 \\
\hline & & superior FD image (\%) & 12 & 97.2 & 6.5 & 83.3 & 100.0 \\
\hline & & insufficient flat detector image (\%) & 12 & 1.4 & 4.8 & 0.0 & 16.7 \\
\hline & & insufficient FD image, EOS image good (\%) & 12 & 0.0 & 0.0 & 0.0 & 0.0 \\
\hline & & superior EOS image (\%) & 12 & 0.0 & 0.0 & 0.0 & 0.0 \\
\hline & & insufficient EOS image (\%) & 12 & 82.6 & 21.5 & 33.3 & 100.0 \\
\hline & & insufficient EOS image, FD image good (\%) & 12 & 81.3 & 21.9 & 33.3 & 100.0 \\
\hline & \multirow[t]{7}{*}{ knee } & number of images (n) & 6 & 4 & 1 & 2 & 4 \\
\hline & & superior FD image (\%) & 6 & 95.8 & 10.2 & 75.0 & 100.0 \\
\hline & & insufficient flat detector image (\%) & 6 & 0.0 & 0.0 & 0.0 & 0.0 \\
\hline & & insufficient FD image, EOS image good (\%) & 6 & 0.0 & 0.0 & 0.0 & 0.0 \\
\hline & & superior EOS image (\%) & 6 & 0.0 & 0.0 & 0.0 & 0.0 \\
\hline & & insufficient EOS image (\%) & 6 & 75.0 & 22.4 & 50.0 & 100.0 \\
\hline & & insufficient EOS image, FD image good (\%) & 6 & 75.0 & 22.4 & 50.0 & 100.0 \\
\hline \multirow[t]{28}{*}{$\begin{array}{l}\text { all assses- } \\
\text { sors }\end{array}$} & \multirow[t]{7}{*}{ large pelvis } & number of images ( $n$ ) & 12 & 46 & 25 & 5 & 62 \\
\hline & & superior FD image (\%) & 12 & 84.4 & 10.7 & 67.7 & 100.0 \\
\hline & & insufficient flat detector image (\%) & 12 & 3.6 & 6.4 & 0.0 & 16.7 \\
\hline & & insufficient FD image, EOS image good (\%) & 12 & 0.4 & 0.8 & 0.0 & 1.7 \\
\hline & & superior EOS image (\%) & 12 & 3.5 & 3.3 & 0.0 & 10.2 \\
\hline & & insufficient EOS image (\%) & 12 & 43.6 & 35.3 & 12.9 & 100.0 \\
\hline & & insufficient EOS image, FD image good (\%) & 12 & 40.4 & 30.8 & 12.9 & 100.0 \\
\hline & \multirow[t]{7}{*}{ small pelvis/hip } & number of images ( $n$ ) & 48 & 39 & 23 & 2 & 62 \\
\hline & & superior FD image (\%) & 48 & 84.3 & 12.6 & 63.3 & 100.0 \\
\hline & & insufficient flat detector image (\%) & 48 & 0.3 & 2.4 & 0.0 & 16.7 \\
\hline & & insufficient FD image, EOS image good (\%) & 48 & 0.0 & 0.0 & 0.0 & 0.0 \\
\hline & & superior EOS image (\%) & 48 & 1.0 & 1.5 & 0.0 & 5.7 \\
\hline & & insufficient EOS image (\%) & 48 & 30.7 & 33.2 & 0.0 & 100.0 \\
\hline & & insufficient EOS image, FD image good (\%) & 48 & 30.4 & 32.7 & 0.0 & 100.0 \\
\hline & \multirow[t]{7}{*}{ knee } & number of images $(n)$ & 24 & 39 & 22 & 2 & 55 \\
\hline & & superior FD image (\%) & 24 & 78.2 & 15.1 & 48.1 & 100.0 \\
\hline & & insufficient flat detector image (\%) & 24 & 0.4 & 0.8 & 0.0 & 1.9 \\
\hline & & insufficient FD image, EOS image good (\%) & 24 & 0.2 & 0.5 & 0.0 & 1.9 \\
\hline & & superior EOS image (\%) & 24 & 3.1 & 3.2 & 0.0 & 9.3 \\
\hline & & insufficient EOS image (\%) & 24 & 21.4 & 33.5 & 0.0 & 100.0 \\
\hline & & insufficient EOS image, FD image good (\%) & 24 & 21.2 & 33.6 & 0.0 & 100.0 \\
\hline & \multirow[t]{7}{*}{ total } & number of images ( $n$ ) & 84 & 40 & 23 & 2 & 62 \\
\hline & & superior FD image (\%) & 84 & 82.6 & 13.2 & 48.1 & 100.0 \\
\hline & & insufficient flat detector image (\%) & 84 & 0.8 & 3.2 & 0.0 & 16.7 \\
\hline & & insufficient FD image, EOS image good (\%) & 84 & 0.1 & 0.4 & 0.0 & 1.9 \\
\hline & & superior EOS image (\%) & 84 & 2.0 & 2.6 & 0.0 & 10.2 \\
\hline & & insufficient EOS image (\%) & 84 & 29.9 & 33.9 & 0.0 & 100.0 \\
\hline & & insufficient EOS image, FD image good (\%) & 84 & 29.2 & 32.9 & 0.0 & 100.0 \\
\hline
\end{tabular}

$\mathrm{FD}=$ Flat Detector 
images were acquired using manual selection of the exposure parameters, so that in a first measurement series the appropriate incident dose was determined to correspond to the flat panel detector system. In a second measurement series, the manufacturer's recommended exposure parameters were used for examination of the lower spinal column. Each exposure was evaluated by three assessors working independently. The indicated positions of the holes were compared with their actual locations. As a result, the contrast resolution capability of the EOS system corresponded to that of the flat panel detector system at the same incident dose. In the case of examinations performed with the manufacturer's recommended exposure parameters, the contrast resolution capability of the EOS system lay between that of the flat panel detector and the storage phosphor system.

The comparable image quality of EOS technology and that of digital flat panel detector radiography described in the phantom tests was not confirmed in clinical application. Instead, the flat panel detector images were rated qualitatively superior to EOS images by a mean $83 \%$ with $\pm 13 \%$ standard deviation. Of the EOS images, $30 \% \pm 34 \%$ were considered diagnostically insufficient.

The discrepancy between the results of the phantom study and actual patient examinations is explained by the fact that phantom studies can only reproduce a simplified simulation of multidimensional biological reality. The $15 \mathrm{~cm}$ wide PMMA scattering body used in the in vitro measurements insufficiently represented the absorption conditions of the human trunk and lower extremities of the largely obese patients involved in the clinical study. The fact that the extent of the obesity of the patients could not be retrospectively determined represents a methodical limitation of the study. Although during phantom measurements sufficient X-ray quanta for adequate image generation arrived at the detector, the relation in the clinical studies between the level of exposure dose, radiation absorption, and scattering within the irradiated body volume and the signal registration at the detector was unfavorable in a clinically-relevant number of patients; consequently the low spatial resolution could not be offset by the high contrast dynamics of the image reception system. In order to increase the signal level registered in the detector input for the generally obese patients in these clinical studies, and thus improve the signal-to-noise level, adaptations to the sagittal whole leg images were performed in conjunction with the manufacturer. These included multiple increases in tube voltage from $95 \mathrm{kV}$ to $125 \mathrm{kV}$ instead of $77 \mathrm{kV}$ to $81 \mathrm{kV}$ for pelvis overview examinations, and $66 \mathrm{kV}$ to $70 \mathrm{kV}$ for knee joints. Adjustment of the exposure parameters prior to the start of the study phase resulted in a reduction of background noise; as a consequence, this resulted in a reduction of detail contrast. In order to avoid exposing the patient to an excessively high organ dose in the course of treatment, an increase compared to the initial implementation of a constant $\mathrm{kV}$ rate $(80 \mathrm{kV}$ to $95 \mathrm{kV}$, depending on the patient's body size), from $200 \mathrm{mAs}$ or $320 \mathrm{mAs}$ to the maximum possible value of $400 \mathrm{mAs}$ was not used. In comparison, $81 \mathrm{kV}$ was used in phantom measurements for both the X-ray stereotactic images as well as for the flat panel detector and storage phosphor radiographs. Some exceptions to this were
EOS images which, according to the manufacturer's recommendation, were produced using a $95 \mathrm{kV}$ tube voltage.

To the best of the authors' knowledge, to-date there are no publications regarding the qualitative comparison of X-ray stereotactic images of entire spines or legs or the diagnostic evaluation of the flat panel detector images of cortical and spongiosa structure. Deschenes et al. compared whole spine images of 50 scoliosis patients using X-ray stereotactic images (EOS, EOS Imaging) and conventional, one-dimensional images (Fuji FCR 7501S, Fuji) [21]. The delineation of anatomical landmarks relevant to angle measurement were evaluated by 4 independent assessors using a four-level scale. To summarize, the quality of the EOS images were rated superior to those of the whole spine images produced by the Fuji system, despite the lower exposure dose. Due to the incomplete description of the methodology and the results, there is some doubt regarding the clinical relevance of the conclusions [2].

Compared to the corresponding values of Dietrich et al. which used a mean dose area product of $9.2 \mathrm{cGyc} \times \mathrm{cm}^{2} \pm$ $4.6 \mathrm{cGyc} \times \mathrm{cm}^{2}$ for 185 consecutive X-ray stereotactic whole leg images, the dose area product in this study was somewhat higher, with $12.5 \mathrm{cGyc} \times \mathrm{cm}^{2} \pm 4.1 \mathrm{cGyc} \times \mathrm{cm}^{2}$ for sagittal images [15]. The diagnostic image quality was not evaluated by Dietrich et al.

In summary, the EOS X-ray stereotactic imaging system, in the context of whole leg imaging, can be employed only for position control. At this juncture, in its current configuration, the system is not suitable for additional morphological skeletal diagnosis. This could change as a result of progress in detector technology leading to greater geometric detector resolution.

\section{Central statements: \\ $\nabla$}

- X-ray stereotactic whole leg images in two perpendicular planes are suitable for the measurement of exact threedimensional angles in complex skeletal regions of a patient in upright position.

- The quality of images acquired using currently available X-ray stereotactic technology, when compared to standard digital flat panel detector radiography, is insufficient for diagnostic assessment of cortical and spongiosa structures.

- Despite equivalent results of reference measurements of a contrast detail phantom (CDRAD type 2.0, Artinis), the $\mathrm{X}$-ray stereotactic system was inferior to flat panel detector technology used in routine clinical diagnostics in a university orthopedic specialty clinic.

- In the case of patients who in the course of medical care underwent full-leg examinations for the diagnosis of synchronous or metachronous position relationships without an intervening change in the findings or who had pelvic overview imaging, it can be stated retrospectively that a flat panel detector image could not have been dispensed with in favor of an EOS image.

\footnotetext{
Affiliations

Dept. of Radiology, University of Cologne Medical School, Cologne

2 Clinic of the Kapuzinerkarree, Aachen

3 Clinic of Orthopedic and Trauma Surgery, University of Cologne Medical School, Cologne
} 
${ }^{4}$ Test Center for Radiation Protection GmbH, Wennigsen
5 Dept. of Medical Statistics, Informatics and Epidemiology, University of
Cologne Medical Faculty, Cologne

\section{Acknowledgements}

The authors would like to thank Mr. Walter Huhn, Ministry of Employment, Integration, and Social Affairs of North RhineWestphalia, and Mr. Dirk Höwekenmeier, regional government of Cologne, for their encouragement and review of the manuscript.

\section{References}

1 Illés T, Somoskeöy S. The EOSTM imaging system and its uses in daily orthopedic practice. International orthopaedics 2012; 36: 1325-1331

2 McKenna C, Wade R, Faria $R$ et al. EOS 2D/3D X-ray imaging system: A systematic review and economic evaluation. Health Technology Assessment 2012; 16: 1366-5278

3 Wybier M, Bossard P. Musculoskeletal imaging in progress: The EOS imaging system. Joint Bone Spine 2013; 80: 238-243

4 Richtlinie für die technische Prüfung von Röntgeneinrichtungen und genehmigungsbedürftigen Störstrahlern - Richtlinie für Sachverständigenprüfungen nach der Röntgenverordnung (SV-RL). vom 9. Januar 2009, geändert durch verschiedene Rundschreiben des BMU bis 1.8.2011

5 Peters S, Sendler V. Prüfstelle für Strahlenschutz GmbH. Klusterfeld 2, 30974 Wennigsen. Gutachten zur Erfüllung der Genehmigungsvoraussetzungen gemäß $\S 3$ Abs. 2 Nr. 5 und Abs. 3 Nr. 2a und b der Röntgenverordnung für den Betrieb des Röntgensystems EOS der Firma biospace med im Klinikum der Universität zu Köln. 03/2010

6 Faria $R$, McKenna $C$, Wade $R$ et al. The EOS 2D/3D X-ray imaging system: A cost-effectiveness analysis quantifiying the health benefits from reduced exposure. Eur J Radiol 2013; 82: e342 - e349

7 Glaser DA, Doan J, Newton PO. Comparison of 3-dimensional spine reconstruction accuracy: Biplanar radiographs with EOS versus computed tomography. Spine 2012; 37: 1391-1397

8 Journé A, Sadaka J, Bélicourt C et al. New method for measuring acetabular component positioning with EOS imaging: Feasibility study on dry bone. International Orthopaedics (SICOT) 2012; 36: 2205- 2209

9 Khalil JG, Nassr A, Maus TP. Physiologic imaging of the spine. Radiol Clin North Am 2012; 50: 599-611

10 Lazennec JY, Rousseau MA, Rangel A et al. Pelvis and total hip arthroplasty acetabular component orientations in sitting and standing posi- tions: Measurements reproducibility with EOS imaging versus conventional radiographs. Orthop Traumatol Surg Res 2011; 97: 373-380

11 Rousseau MA, Laporte S, Chavary-Bernier E et al. Reproducibility of measuring the shape and three-dimensional position of cervical vertebrae in upright position using the EOS stereoradiography system. Spine 2007; 32: 2569-2572

12 Somoskeöy S, Tunyogi-Csapó M, Bogyó C et al. Accuracy and reliability of coronal and sagittal spine curvature data based on patient-specific three-dimensional models created by the EOS 2D/3D imaging system. Spine J 2012; 12: 1052 - 1509

13 Buck FM, Guggenberger R, Koch PP et al. Femoral and tibial torsion measurements with 3D models based on low-dose biplanar radiographs in comparison with standard CT measurements. Am J Roentgenol 2012; 199: W607-W612

14 Thelen P, Delin C, Folinais D et al. Evaluation of a new low-dose biplanar system to assess lower-limb alignement in 3D: a phantom study. Skeletal Radiol 2012; 41: 1287-1293

15 Dietrich JT, Prirrmann WA, Schwab A et al. Comparison of radiation dose, workflow, patient comfort and financial break-even of standard digital radiography and a novel biplanar low-dose X-ray system for upright full-length lower limb and whole spine radiography. Skeletal Radiol DOI: 10.1007/s00256-013-1600-0

16 Deutsche Referenzzentren für Mammographie. Prüfanleitung für die Durchführung der ergänzenden Prüfpositionen nach EPQC 4th Edition für digitale Mammographie-Systeme. Leitfaden der deutschen Referenzzentren für Mammographie. Version 1.4 vom 14. September 2009. https://www.umwelt-online.de/recht/energie/strahlen/rl/epqc. htm. 26.4.2013

17 Blendl C, Schreiber AC, Buhr H. Results of an automatic evaluation of test images according to PAS 1054 and IEC 6220-1-2 on different types of digital mammographic units. RÖFO 2009; 181: 979-988

18 Blendl C, Loos C, Eiben B. Comparison of two automatic evaluation methods on images of the CDMAM test phantom. Fortschr Röntgenstr 2009; 181: 637-643

19 Figl M, Semturs F, Kaar M et al. Dose sensitivity of three phantoms used for quality assurance in digital mammography. Phys Med Biol 2013; 58: $\mathrm{N} 13-\mathrm{N} 23$

20 Sommer A, Lenzen H, Blaser D et al. Guideline for the additional test positions according to the EPQC 4th Edition for Digital Mammography Systems. RÖFO 2009; 181: 845-850

21 Vahey K, Ryan E, McLean D et al. A comparison between the electronic magnification (EM) and true magnification (TM) of breast phantom images using a CDMAM phantom. Eur J Radiol 2012; 81: 1514-1519

22 Deschenes S, Charron G, Beaudoin G et al. Diagnostic imaging of spinal deformities reducing patients radiation dose with a new slot-scanning X-ray Imager. Spine 2010; 35: 989-994 